\title{
Recommended Corrections to the Classification of Shigella flexneri on a Genetic Basis
}

\author{
V. G. PETROVSKAYA AND V. M. BONDARENKO \\ Gamaleya Institute for Epidemiology and Microbiology, Moscow D98, U.S.S.R.
}

The analysis of immunochemical and genetic studies resulting in recommendations for corrections and unification of Shigella flexneri classification is presented in this paper.

As is already known, investigators have faced many difficulties in the classification of Shigella. Only in 1954 did the International Commission adopt the International Classification of Shigella, and additional corrections were introduced in 1958. In 1966, at the International Congress of Microbiology in Moscow, Ewing and Carpenter (5) recommended corrections to the International Classification of 1958. However, until now there have been differences in the opinions of the existing classification, especially of Shigella flexneri $(4,21,25)$. Investigators of different countries have indicated the necessity of designating serovar 6 (Shigella newcastle) as an $S$. flexneri subspecies and even an independent species on the basis of significant differences in the properties of this serovariant $(8,22-25)$. The data on the necessity to subdivide serovar 5 into subserovars $5 \mathrm{a}$ and $5 \mathrm{~b}$ were presented by Khomenko (13) and Timakov et al. (25).

Shigella are divided into serovars characterized by the presence of serovar-specific antigens (I to VI) and subserovars (mainly "a" and " $b$ "), depending on the combination of these specific antigens with the so-called group-specific antigens (namely $3,4,6$, or 7,8 ). Strains devoid of specific antigens are designated as group variants: " $y$ " $(-: 3,4)$ and " $x "(-: 7,8)$. Instability of the antigenic structures of $S$. flexneri strains resulted in investigators complicating the scheme by adding new subspecific varieties $-1 \mathrm{c}, 4 \mathrm{c}, 4 \mathrm{~d}$, and so on $(4,21)$.

Recent data on the immunochemical structure of $S$. flexneri $\mathrm{O}$ antigen and the genetic control of specific and group-specific antigens not only explain the antigenic variability of these bacteria but, from our point of view, permit the unification of their classification on the basis of these findings.

\section{RESULTS AND DISCUSSION}

Luria and Burrous (18) first carried out the recombination between Shigella and the donor strain Escherichia coli $\mathrm{K}-12 \mathrm{HfrC}$. It was shown that 95 to $97 \%$ of $\mathrm{lac}^{+}$hybrids of $S$. flexneri of serovars $2 \mathrm{a}, 2 \mathrm{~b}$, and $4 \mathrm{a}$ lost the corresponding characteristic antigens with transition into variant y $(-: 3,4)$. Later, in a series of similar matings of the representatives of serovars 1 to 6 , it was demonstrated that nearly all strains of serovars of $S$. flexneri (with the exclusion of serovar 6) could be turned into group variant y $(1,20,24,25)$.

This observation was very important as it confirmed the suggestion of Simmons made on the ground of immunochemical studies that lipopolysaccharide (LPS) $O$ antigen of all serovars of $S$. flexneri contains group-specific antigen 3,4 as a main primary structure (23).

$S$. flexneri base chain has repeating units with the following structure: Rha-1,3- or 1,2Rha-1,6- $N$-acetylglucosamine (21). Component 4 is determined by the group Rha-1,3-Rha (7). It is interesting that the avidity of antibodies 3,4 is directed not only against this rhamnose residue but also against the (1-6) linkage to the $N$ acetylglucosamine and less so to the (1-3) linkage from the terminal rhamnose (23).

It was further shown immunochemically that serovar-specific antigens I-II-IV-V and groupspecific factor 7,8 are the result of modification of antigen 3,4. The biosynthesis of the abovementioned group of antigens is completed from a precursor variant y (antigen 3,4) polysaccharide by incorporating $\alpha$-glucosyl secondary side chains in a position that is unique to each sero$\operatorname{var}(21,23)$.

Antigen III and group-specific factor 6 contain acetyl groups in LPS in contrast to the above-mentioned antigens. It was stated that factor 6 was defined by group 2-O-Ac-Rha and antigen III by grouping (2-O-Ac-Rha)- $N$-acetylglucosamine (17). By comparing these data with the above-mentioned findings of Freedländer et al. (7), one can conclude that antigen 6 appears as a result of acetylation of factor 4, and antigen III appears as a result of acetylation of complex 3,4 .

Our investigation of genetic control of $S$. flexneri serovar and group antigens in recombina- 
tion experiments with donor strains of $E$. coli K-12 $(1,20,24)$ and other experiments of transfer of antigen 3,4 from Shigella to $E$. coli K-12 (6) allowed us to conclude that factor 3,4 is controlled by the chromosomal gene localized near the his marker (according to our data cotransduction of $\mathrm{his}^{+} \mathrm{a} 3,4^{+}$is $28.5 \%$ [1]).

We have postulated that the Tp locus situated near the lac operon is responsible for the synthesis of antigens I-II-IV-V (20, 24). As is already known, conversion of $S$. flexneri $\mathrm{O}$ antigen followed by an appearance of antigens III-IV-V and 7,8 was carried out by means of isolated corresponding phages $(10,11,20)$. It has been shown that the Tp locus is a site of attachment of the corresponding prophages. The prophage determining factor 7,8 attaches at the same site $(1,20)$.

As far as antigen 6 is concerned, the loss of this factor by some of the $h^{+}{ }^{+}$hybrids of $S$. flexneri $1 \mathrm{~b}$ obtained in crosses with different donor strains of $E$. coli $\mathrm{K}-12$ was shown in our previous experiments (20). In another series of experiments the loss of antigen III by $l a c^{+}$hybrids of $S$. flexneri $3 \mathrm{a}$, obtained by mating with active donor strains of $E$. coli $\mathrm{K}-12$ ( $\mathrm{HfrH}$ and S160), was demonstrated (25). Among lac ${ }^{+}$hybrids devoid of factor III, we observed that the clones were also devoid of antigen 6 . These observations indicated the existence of two sites on the $S$. flexneri chromosome that were important for genetic control of the synthesis of group-specific factor 6 -one localized in the $h i s$ region, the other localized in the region of the lac marker.

Later we confirmed our observations on the loss of antigen 6 by a part of the $h i s^{+}$hybrids of $S$. flexneri $1 \mathrm{~b}$. However, having used phages specific for S- and R-forms of $S$. flexneri, we came to the conclusion that the loss of antigen 6 by part of $h i s^{+}$hybrids had been connected to the disturbance in the synthesis of antigen 3,4 as the acceptor of acetyl groups (2). We could not also transfer factor 6 with the his marker in interspecific crosses. On the contrary, in the intraspecific mating of $y$ and $x$ variants of $S$. flexneri with donor strain of $S$. flexneri $3 \mathrm{c}$ (III:6), we succeeded in transferring factor 6 and antigen III with the lac marker $(1,2)$.

The transfer of the antigens was rather independent; however, in no case did we observe hybrids acquiring antigen III without factor 6 while in cross with variant $y$; for instance, $8 \%$ of the $l a c^{+}$hybrids acquired only factor 6 , and $24 \%$ acquired both antigens 6 and III simultaneously (Table 1).

The genes determining the formation of factor 6 and antigen III were inherited by $32 \%$ and by $24 \%$ of the $\mathrm{lac}^{+}$hybrids, respectively. We then succeeded in transferring antigens III and 6 to the his $^{+}$hybrid of $E$. coli K-12 which had acquired antigen 3,4 in a previous cross. In this case, the $\mathrm{pro}^{+}$marker was used as the selective. $\mathrm{pro}^{+}$hybrids simultaneously acquiring the lac marker as unselective were characterized by an ability to synthesize factor 6 in $100 \%$, and only 17 to $19 \%$ from them acquired antigen III.

These observations confirm our suggestion on the localization of determinants of the above-mentioned antigens in the lac-pro region and on the closer localization of gene a 6 to these markers on the Shigella chromosome. An investigation of the serological properties of hybrids $\mathrm{a6}^{+} \mathrm{aIII}{ }^{+}$in a tube reaction of agglutination with living and heated bacteria helped identify the characteristics of the antigen acquired with the characteristics of antigens III and 6 of wild strains of $S$. flexneri serovar 3c (III:6).

Recently Gemski et al. (9) isolated a phage from strain $S$. flexneri 3 a and reproduced the conversion of $\mathrm{O}$ antigen of group variant $\mathrm{y}$ followed by an appearance of group factor 6 . A similar conversion was reproduced in the $h_{i s}^{+} \mathrm{a} 3,4^{+}$hybrid of $E$. coli K-12. Serological study and chemical analysis of LPS of the con-

TABLE 1. Antigenic structure of lac ${ }^{+}$hybrids obtained from mating $S$. flexneri variants $y$ and $x$ with donor strain $S$. flexneri $3 c$ (III:6)

\begin{tabular}{|c|c|c|c|c|c|}
\hline \multirow{2}{*}{ Recipient strain } & \multirow{2}{*}{$\begin{array}{l}\text { Selective } \\
\text { marker }\end{array}$} & \multirow{2}{*}{$\begin{array}{l}\text { No. of hy- } \\
\text { brids }\end{array}$} & \multicolumn{2}{|c|}{ No. of hybrids with antigen } & \multirow{2}{*}{$\begin{array}{l}\text { Antigenic for- } \\
\text { mula of hybrids }\end{array}$} \\
\hline & & & 6 & III & \\
\hline $\begin{array}{l}\text { S. flexneri variant y } \\
(-: 3,4)^{a}\end{array}$ & $\operatorname{lac}^{+}$ & 100 & 32 & 24 & $\begin{array}{l}-: 3,4 ; 6 ; \\
\text { III:3,4;6; or } \\
\text { III: } 6\end{array}$ \\
\hline $\begin{array}{l}\text { S. flexneri variant } \mathrm{x} \\
(-: 7,8)^{b}\end{array}$ & $l a c^{+}$ & 50 & 12 & 8 & $\begin{array}{l}-: 6 ; 7,8 ; \\
\text { III: } 3,4 ; 6,8 ; \text { or } \\
\text { III } 6 ; 7,8\end{array}$ \\
\hline
\end{tabular}

\footnotetext{
${ }^{a}$ Linkage rate: $\operatorname{lac}^{+} \mathrm{ab}^{+}, 32 \%$; lac $^{+}$aIIII+ $24 \%$.

${ }^{b}$ Linkage rate: $\mathrm{lac}^{+} \mathrm{a6}{ }^{+}, 24 \%$; $\mathrm{lac}^{+} \mathrm{aIII}{ }^{+}, 16 \%$.
} 
vertants confirmed that factor 6 detected in bacteria was in fact an acetylated form of rhamnose (9).

On the basis of the above-mentioned data, it could be concluded that group-specific factor 6 , being the acetylated form of antigen 3,4 is controlled by a prophage localized on chromosome of $S$. flexneri in the region of lac-pro markers. This phage is perhaps also necessary for the expression of antigen III. An analysis of closely related structures of antigen III and group factor 6 suggested that the determinant of antigen III is probably responsible for the linking of acetyl groups to the other atom of the same nonterminal rhamnose.

Thus antibodies of antigen III, like antibodies to factor 3,4 (23), are more directed against the 1,6 linkage to the $N$-acetylglucosamine than to the acetylated form of Rha-1,3-Rha which presents immunodominant sugar of factor 6 .

It should be mentioned that although antigens 6 and III are the acetylated form of the same nonterminal rhamnose according to immunochemical data, they differ from each other by physicochemical properties: antigen III is more thermosensitive but less susceptible to the treatment with $1 \mathrm{~N} \mathrm{HCl}$, in comparison with antigen 6 (14).

The data obtained as a whole explained first of all the variability of the antigenic structure of $S$. flexneri serovars 1 to 5 . It is evident that all serovar-specific antigens and group factors 6 and 7,8 are related to converting phages. It provides the possibility of differences not only of antigenic characteristics of the strains of the same serovar, but of clones of the same strain as well.

Theoretically the appearance of factor 3,4 could occur in the population of the representatives of all serovars of $S$. flexneri. In our previously mentioned studies the dependence of the behaviour of different serovar-specific antigens on their combination with different group-specific factors was stated $(20,24)$. Lac ${ }^{+}$hybrids of subtype a (1a, 2a, 4a, 5a), in combination with factor 3,4 , lost corresponding serovar-specific antigens with transition into group variant $y$ $(15,18,24)$, whereas strains of serovars $1 b$ and $4 \mathrm{~b}$ (combination with factor 6 ) were turned into serovar $3(16,20,24)$.

The behaviour of antigen $\mathrm{V}$ in combination with factor 7,8 is more complicated. $\mathrm{Lac}^{+}$hybrids obtained from a cross with $E$. coli $\mathrm{K}-12$ $\mathrm{HfrC}$ did not lose either $\mathrm{V}$ or 7,8 antigens. In mating with the more effective donor $(E$. coli $\mathrm{K}-12 \mathrm{HfrH}$ ), they were turned into $\mathrm{x}$ or $\mathrm{y}$ variants (25).
Available information suggests that the representatives of subserovars a (1a, 2a, 4a, 5a) are monolysogenic strains (with the exclusion of those of serovar 3a). Serovar 3c (III:6) is monolysogenic also. Serovars $2 b$ and $5 b$ are dilysogenic (phages 7,8 and II, and V, respectively). Serovars $1 \mathrm{~b}$ and $4 \mathrm{~b}$ are also dilysogenic (phages 6 and I, and IV, respectively), as well as serovars $3 a$ and $3 b$ (phages 6 and 7,8).

On the basis of genetic findings we suggested that phage 7,8 was characterized by a different kind of linkage with chromosome (tandem?) than were prophages I-II-IV-V. So, in conversion, prophages I-II-IV-V behaved as alleles (one phage is replaced by another); the possibility of subsequent lysogenisation by phages II and 7,8 with the formation of serovar $2 b$ (II:7,8) as well as transition of a variant $\times(-: 7,8)$ into $5 b(V: 7,8)$ was demonstrated $(10,11)$.

Data of immunochemical investigations could now present stereochemical formulas of polysaccharide determinants of $S$. flexneri $O$ antigen and explain some peculiarities of serological reactions (23). It has been suggested, for instance, that serovar $2 \mathrm{a}$ was formed as a result of incorporation of $\alpha$-glucosyl secondary side chains along the "down" surface of the main structure of antigen 3,4 and thus was characterized by the formula II:3,4, whereas similar incorporation of $\alpha$-glucosyl sequences along the "upper" surface of antigen 3,4a completely overcovered this structure (variant $x[-: 7,8]$, serovar $5 \mathrm{~b}[\mathrm{~V}: 7,8])$. Nevertheless, the 3,4 determinant is a cryptic situation in these antigens.

On the contrary the incorporation of $\alpha$-glucosyl to $N$-acetyl-D-glucosamine (serovar 1 ) leaves factor 4 "opened," masking only component 3 . This explains why antigen 6 (acetylated form of factor 4) is always serologically registered in the strains of serovar $1 \mathrm{~b}$ (I:6) and $4 \mathrm{~b}$ (IV:6), whereas antigen III is presented in a cryptic form $(21,23)$ and is revealed only after the loss of antigens I or IV, respectively $(15,24)$.

As for $S$. flexneri 6 ( $S$. newcastle), we presented earlier (25) a summary table of differences (in biochemical, synthetic properties, sensitivity to phages and colicins, and so on) existing between bacteria of this serovar 6 and $S$. flexneri serovars 1 to 5 .

On the basis of significant differences discovered in the structure of LPS of $S$. newcastle, Simmons does not consider this serovar as one of the serovars of $S$. flexneri (23). Recently Katznellenbogen et al. (12) showed that antigen VI corresponds to an O-specific side chain of LPS of $S$. newcastle. The immunodeterminant group of it is rhamnosyl-1,3- $N$-acetyl-D-galactosamine. Hence it is evident that antigen VI 
includes $N$-acetylgalactosamine instead of $N$ acetylglucosamine characteristic for $S$. flexneri, and that O LPS of serovar 6 does not include real group factor 3,4 . The core structure of $S$. newcastle LPS is also not identical to that of $S$. flexneri (23).

It was shown earlier that, in contrast to the genetic determinants responsible for the synthesis of serovar-specific antigens I to $\mathrm{V}$ of $S$. flexneri, the determinant of antigen VI was not mapped in the lac-pro region $(1,25)$. In subsequent work, antigen VI was transferred to $E$. coli K-12 used as recipient from donor strain $S$. newcastle (19).

In the first experiment with selection for the $\mathrm{arg}^{+}$marker, only 2 hybrids from 85 studied acquired antigen VI. Only these 2 hybrids also acquired $\mathrm{his}^{+}$as an unselective marker. Furthermore, the localization of determinant of antigen VI near the his marker was proved (linkage rate of $\mathrm{his}^{+} \mathrm{aVI} \mathrm{Cl}^{+}$was $45.3 \%$; Table 2).

Analysis of all data presented results in our recommending the following corrections to the existing classification of $S$. flexneri and its unification (Table 3).

First of all we propose the separation of $S$ newcastle (serovar 6) from $S$. flexneri since, in light of the recent data, its $O$ antigen does not

TABLE 2. Characteristics of arg ${ }^{+}$and his $^{+}$hybrids of $E$. coli K-12 PA309 obtained from crosses with $S$. newcastle donor strain ${ }^{a}$

\begin{tabular}{ccc}
\hline Selective markers & $\begin{array}{c}\text { No. of hybrids } \\
\text { studied }\end{array}$ & $\begin{array}{c}\text { Rate of transfer } \\
\text { of antigen VI } \\
(\%)\end{array}$ \\
\hline $\mathrm{arg}^{+}$ & 85 & 2.3 \\
$\mathrm{his}^{+}$ & 53 & 45.3 \\
$\mathrm{arg}^{+} \mathrm{his}^{+}$ & 50 & 44.0 \\
\hline
\end{tabular}

${ }^{a}$ Donor strain was $S$. newcastle (VI:-), asp ${ }^{-}$nic $^{-}$ cys $^{-} \mathrm{B}_{1}^{-}$; recipient was $E$. coli $\mathrm{K}-12 \mathrm{arg}^{-} \mathrm{his}^{-}$trp $^{-}$ $t h r^{-} l e u^{-} \mathrm{B}_{1}^{-}$.

TABLE 3. Recommended unification of $S$. flexneri classification

\begin{tabular}{ccl}
\hline Serovar & Subserovar & $\begin{array}{l}\text { Abbreviated an- } \\
\text { tigenic formula }\end{array}$ \\
\hline 1 & $1 \mathrm{a}$ & $\mathrm{I}: 4$ \\
& $1 \mathrm{~b}$ & $\mathrm{I}:(4) ; 6$ \\
2 & $2 \mathrm{a}$ & $\mathrm{II}: 3,4$ \\
& $2 \mathrm{~b}$ & $\mathrm{II}: 7,8$ \\
3 & $3 \mathrm{a}$ & $\mathrm{III}:(3,4) ; 6$ \\
& $3 \mathrm{~b}$ & $\mathrm{III}:(3,4) ; 6 ; 7$ \\
4 & $4 \mathrm{a}$ & IV:3,4 \\
& $4 \mathrm{~b}$ & IV: $(3,4) ; 6$ \\
5 & $5 \mathrm{a}$ & $\mathrm{V}:(4)$ \\
& $5 \mathrm{~b}$ & $\mathrm{~V}:(7)$ \\
& Group var. $\mathrm{x}$ & $-: 7,8$ \\
& Group var. $\mathrm{y}$ & $-: 3,4$ \\
\hline
\end{tabular}

include real factor 3,4 specific for Shigella subgroup B (12). In addition, our genetic data showed different locations on the chromosome of the determinants responsible for serovar-specific antigens I-V and VI $(1,19,25) . S$. newcastle may be considered one of the serovars of Shigella boydii. Immunochemical studies of LPS of these bacteria showed variety in the LPS structure. Among eight chemovars of $S$. boydii LPS, two of them (IV and V) contain galactosamine in the $\mathrm{O}$-specific side chains. The chemovar of serovar 6 (S. newcastle) may be placed between III and IV as an independent serovar in the scheme of Dmitriev et al. (3).

As to classification of $S$. flexneri (serovars 1 to 5), we think that it needs unification: all of the serovars could be divided into only two subserovars, a and b. In our previous work we presented genetic evidence of the existence of two subserovars of $S$. flexneri serovar 5:5a and $5 \mathrm{~b}$ (25). According to Khomenko (13) the strains of these serovars circulate independently in nature. This is evident from immunochemical investigations as well $(21,23)$.

Contrary to the other serovars, serovar 3 was divided into 3 subvarieties: the simplest formula (III:6) was designated $3 \mathrm{c}$, while the more complex formula (III:6;7,8) was designated 3a. The increase of the number of serovarieties was connected with the detection of factor 3,4 - serovar 3b (III:3,4;6,7,8). Ewing and Carpenter (5) designated strains with antigenic formula III: $6 ; 7,8$, III:3,4;6, and III: 6 as $3 \mathrm{a}, 3 \mathrm{~b}$, and $3 \mathrm{c}$, respectively.

The data of Table 1 show that the transfer of antigens III and 6 to $y$ variant leads to the formation of kinds of strains: with the masked antigen 3,4 (that is III:6) or with the preserved one (III:3,4;6). Similarly the strains of serovar 3 were formed from $x$ variant (carrying the corresponding phage 7,8 ) with two variants also: with antigen 3,4 or without it (which corresponded to subvarieties $3 \mathrm{~b}$ [III:3,4;6;7,8] and $3 \mathrm{a}$ [III: $6 ; 7,8]$ of International Classification).

The possibility of detection of antigen 3,4 in different clones of strains of subvarieties $3 a$ and $3 \mathrm{c}$ confirmed these findings (14) and provides no reason to introduce additional subserovars. In our opinion serovar 3 should be divided as other serovars into two subvarieties, $a$ and $b$. The former serovar $3 \mathrm{c}$, since it is simpler and monolysogenic (phage 6), should be designated 3a (III:6) by analogy with the serovars $1 \mathrm{a}, 2 \mathrm{a}, 4 \mathrm{a}, 5 \mathrm{a}$ (Table 3). Double lysogenic strains with factor 7,8 should be designated $3 \mathrm{~b}$ (III:6;7,8). In both cases antigen 3,4 could be put into brackets.

As to variant $\times(-: 7,8)$, then, in spite of the fact that the latter is an analogue of serovar- 
specific antigens I-II-IV-V (glycosylated form of antigen 3,4 ), we think that its former designation (group-specific factor 7,8 ) should be preserved (Table 3 ). The prophage 7,8 , which determines this antigen, differs from the prophages determining serovar-specific antigens I-II-IVV. As was mentioned above, prophages of serovar-specific antigens are mutually substituted, but it is possible subsequently to lysogenize with serovar-specific phages and phage 7,8 .

\section{REPRINT REQUESTS}

Address reprint requests to: Dr. V. G. Petrovskaya, Gamaleya Institute for Epidemiology and Microbiology AMS USSR, ul. Gamaleyi 18, Moscow 123098, U.S.S.R.

\section{LITERATURE CITED}

1. Bondarenko, V. M. 1976. Die genetische Kontrolle der O-antigen Lipopolysaccharid-Synthese bei Shigella flexneri und die Bedeutung einselner Komponenten für die Virulenz der Dysenterie-Bakterien. Z. Gesamte Hyg. Ihre Grenzgeb. 22:1-6.

2. Bondarenko, V. M., and V. G. Petrovskaya. 1977. Studies on the genetic control of $S$. flexneri serovar III and group-specific 6 antigens. Z. Microbiol. (Moscow) 4:79-86.

3. Dmitriev, B. A., L. V. Backinowsky, N. K. Kochetkov, and N. A. Khomenko. 1973. Immunochemical studies on Shigella boydii lipopolysaccharides. Eur. J. Biochem. 34:513-518.

4. Edwards, P. R., and W. H. Ewing. 1972. Identification of Enterobacteriaceae. Burgess Publishing Co., Minneapolis.

5. Ewing, W. H., and P. Carpenter. 1966. Recommended designations for the subserotypes of Shigella flexneri. Int. J. Syst. Bacteriol. 16:145-149.

6. Formal, S. B., P. Gemski, L. Baron, and E. H. LaBrec. 1970. Genetic transfer of Shigella flexneri antigens to Escherichia coli $\mathrm{K}-12$. Infect. Immun. 1:279-287.

7. Freedländer, E., R. Manson, and D. Simmons. 1971. The immunochemistry of Shigella flexneri $\mathrm{O}$ antigens: an analysis of the antigen determinants of group factors 4 and 3,4. Immunology 20:11-16.

8. Gekker, V. D., E. D. Ravitch-Birger, and Y. A. Belaya 1965. The position of Newcastle bacteria in the classification of the Shigella. Int. Bull. Bacteriol. Nomencl. Taxon. 15:133-136.

9. Gemski, P., D. E. Koeltzow, and S. B. Formal. 1975. Phage conversion of Shigella flexneri group antigens. Infect. Immun. 11:685-691.

10. Giammanco, G. 1968. Conversion lysogénique de caractères antigéniques de Shigella flexneri (antigène II de type et complexe 7,8 de groupe). Ann. Inst. Pasteur 114:63-76.

11. Giammanco, G., and D. Natoli. 1969. Conversion antigéniques chez Shigella flexneri. II. Effects de la lysogénisation de cultures sérotype 2, variante " $x$ " per un phage issu d'une culture 5. Ann. Inst. Pasteur. 117:16-25.

12. Katznellenbogen, E., M. Mulczyk, and E. Romanowska. 1976. Structural studies on $O$ specific polysaccharide of Shigella flexneri serotype 6. Eur. J. Biochem. 61:191-197.

13. Khomenko, N. A. 1967. Serological varieties of Shigella flexneri serotype 5. Int. J. Syst. Bacteriol. 17:53-55.

14. Khomenko, N. A., and B. S. Kiseleva. 1968. The resistance of antigenic components of Shigella flexneri. $\mathrm{Z}$. Microbiol. (Moscow) 3:57-64.

15. Lachowicz, T., M. Lagowska, and J. Kolodynski. 1972. The antigenic structure of $E$. coli and Shigella flexneri hybrids. Arch. Roum. Pathol. Exp. Microbiol. 31:39-44.

16. Lachowicz, T., M. Mulczyk, and N. Malerz. 1966. Hybrids of $E$. coli and Shigella flexneri $1 \mathrm{~b}$. Arch. Immunol. Ther. Exp. 14:405-409.

17. Lindberg, B., J. Lönngren, E. Romanowska, and U. Ruden. 1972. Location of O acetyl groups in the Shigella flexneri types $3 \mathrm{c}$ and $4 \mathrm{~b}$ lipopolysaccharides. Acta Chem. Scand. 26:3808-3810.

18. Luria, S. E., and J. W. Burrous. 1957. Hybridization between Escherichia coli and Shigella. J. Bacteriol. 74:461-476.

19. Makletsova, Y. I., and V. G. Petrovskaya. 1976. Genetic control of the VI typespecific antigen of S. newcastle. Z. Microbiol. (Moscow) 1:44-48.

20. Petrovskaya, V. G., and V. M. Bondarenko. 1971. The genetic control of Shigella flexneri type and group antigens, p. 389-398. In Perez-Miravete and Pelarz (ed.), Recent advances in microbiology. Tenth International Congress of Microbiology, Mexico, 1970.

21. Seltmann, G. 1972. Untersuchungen zur Antigenstruktur von Shigellen. Z. Allg. Mikrobiol. 12:497-520.

22. Slopek, S., and M. Mulczyk. 1967. Concerning the classification of Shigella flexneri B bacilli. Arch. Immunol. Ther. Exp. 15:600-608.

23. Simmons, D. A. R. 1971. Immunochemistry of Shigella flexneri $\mathrm{O}$ antigen: a study of structural and genetic aspects of the biosynthesis of cell-surface antigens. Bacteriol. Rev. 35:117-148.

24. Timakov, V. D., V. G. Petrovskaya, and V. M. Bondarenko. 1970. Studies on the genetic control of Shigella subgroup B type specific antigens. Ann. Inst. Pasteur 118:3-9.

25. Timakov, V. D., V. G. Petrovskaya, V. M. Bondarenko, and N. A. Khomenko. 1972. Some genetic data concerning Shigella flexneri serotypes 5 and 6 . Int. J. Syst. Bacteriol. 22:149-154. 